\title{
Maternal-Fetal Attachment in Adolescents in Thailand
}

\section{Khamsawarde $\mathrm{N}^{*}$}

Si Maha Sarakham Nurse College, Thailand

*Corresponding author: Nonglak Khamsawarde, Si Maha Sarakham Nurse College, Maha Sarakham Province, Thailand, Email: nonglakk@smnc.ac.th

\section{Review article}

Volume 3 Issue 1

Received Date: February 11, 2019

Published Date: February 27, 2019

DOI: $10.23880 /$ mjccs-16000208

\section{Abstract}

The concept of maternal-fetal attachment in Thailand is not clearly defined. It is used interchangeably will other terms such as engage and attachment. This article discusses the terms of engage and attachment. In addition, significant of the term maternal-fetal attachment, and the intervention of maternal-fetal attachment is discussed in this article.

Method; this article reviews the literature published in 2013-2018. The literature published from aboard and Thailand. The language of article was English and Thai. The results show that "engage" refers to tie and "attachment" refer to careseeking and bond for care-giving. The maternal-fetal attachment is a process between pregnant adolescents and her fetus. In the western countries, the maternal-fetal attachment are effecting by seeing an ultrasound of the fetus, the experience of fetal movement or quickening, the fetal movement counting, and the pictorial. In Asia countries, it is reported that the effect is by abdominal palpation of Leopold's maneuvers. Generally in Thailand, the most common term used is maternalinfant attainment which refers to post delivery. Therefore, the maternal-fetal attachment is not addressed. So the term maternal-fetal attachment needs to be clarified.

Keywords: Engage; Attachment; Maternal-Fetal Attachment; Adolescent; Intervention

\section{Introduction}

The concept of maternal-fetal attachment in adolescent in Thailand is not clearly defined. In addition, significant of the term maternal-fetal attachment and the intervention of maternal-fetal attachment is discussed in this article.

The terms, engage, engagement, and attachment have been used interchangeably in the literature. Engage is a verb and engagement is a noun. Engage refers to tie, to succeed in attracting and keeping somebody's attention and interest [1]. According to Bowlby attachment is defined as "behaviors that supported proximity to an attachment figure (the mother) as a predictable outcome and who see volutionary function was protection of the infant from danger". In addition, Bowlby referenced "attachment" as care-seeking and "bond" as care-giving.
The terms such as maternal fetal bond, maternal-fetal tie, and maternal-fetal attachment (with antenatal and prenatal also used in place of fetal) are used to denote the interaction in question [2].

Bowlby described the core of attachment to be a child's preferred wish for contact with its primary caregiver when feeling of threats occur [3]. Although some authors have rejected the term "attachment" due to its association with "careseeking" as compared with "caregiving" (Walsh, 2010), this connection has variously been described as "maternal-fetal attachment", "prenatal attachment" and "maternal-fetal bonding" [4].

Young reported that the attachment is a process by which an individual creates an attachment to another individual [5]. Cranley used the term of "Maternal-Fetal Attachment (MFA)" for study during the antenatal period. 


\section{Medical Journal of Clinical Trials \& Case Studies}

In regards to maternal-fetal attachment, Cranley (p. 282) defined this as "the extent to which women engage in behaviors that represent an affiliation and interaction with their unborn child" [6]. Muller used the word prenatal attachment, defined as "the unique, affectionate relationship that develops between a woman and her fetus" (p.11) [6]. Condon and Corkindale (1997, p. 359) defined prenatal attachment as "the emotional tie or bond which normally develops between the pregnant parent and her unborn child"

\section{Significant of the Term Maternal-Fetal Attachment}

Prenatal attachment can be described as the parent's emotions, perceptions, and behaviors that are related to the fetus [7]. Nupech [8] reported that the word "attachment" used during pregnancy and the word "bonding" be used for postpartum. Prenatal attachment is defined as the extent to which women participate in behaviors that represent a connection or interaction with their unborn child [5]. In addition, maternal-fetal bonding, also known as prenatal attachment, is defined as an emotional tie that develops between expectant parents and their fetus [5,7]. Hurtado [5] used the word maternalfetal bonding to study a program to improve maternalfetal attachment among Latina mothers.

Sombutsook, Chunuan, and Punthmathrith [9] used the terms prenatal attachment, maternal-fetal attachment, prenatal bonding, maternal-fetal bonding, prenatal tie, maternal-fetal tie, and maternal-fetal relationship for further defining the term of attachment. The method used a concept analysis. The results reveal that prenatal attachment is concern and protection, thinking about the unborn baby, communication and interaction, love, preparedness, and thinking about long term relationships. Antecedents include being pregnant, attitudes of pregnancy, the cognitive ability to conceptualize the fetus as a person, and maternal awareness of the fetus. The consequences are health practices, neonatal outcomes, postnatal attachment, maternal role, maternal-infant adaptation, and the well-being of the child.

In conclusion, engagement is the same as the term attachment, prenatal attachment, maternal-fetal attachment, prenatal bonding, maternal-fetal bonding, prenatal tie, maternal-fetal tie, and maternal-fetal relationship. It refers to the tie between a mother and her fetus by communication, and interaction. The outcome is care seeking, love, protection, health practices, maternal role, and neonatal outcomes.

\section{Intervention about Maternal-Fetal Attachment}

The health practice of pregnant adolescents had intervention related to maternal-fetal attachment such as in Korea, Japan, Netherlands, and Thailand.

In Korea, Shin and Kim [10] studied music therapy on anxiety, stress and maternal-fetal attachment in pregnant women before 14 weeks of gestation during a transvaginal ultrasound. The results revealed that music therapy was effective in decreasing anxiety in pregnant women during a transvaginal ultrasound examination. But no significant difference was identified in stress and maternal-fetal attachment.

In Japan, Nishikawa and Sakakibara [11] studied the effect of a nursing intervention program using abdominal palpation of Leopold's maneuvers on maternal-fetal attachment. The subjects were Japanese women aged less than 40 years old with singleton pregnancies. The results revealed that the abdomen palpation was shown to be effective for promoting maternal-fetal attachment in normal expectant mothers.

In the Netherlands, Bakel, Maas, Vreeswijk, \& Vingerhoets [7] studied the pictorial representation of attachment: measuring the parent-fetal relationship in expectant mothers and fathers. The subjects were 352 primi-or multiparous pregnant women at 26 weeks gestational age, and 268 partners from a community in the Netherlands. The results revealed that the pictorial representation of attachment measuring the parent-fetal relationship in expectant mothers and fathers showed a positive relationship in fathers and mothers.

In Thailand, the literature reviewed about maternal fetal attachment and the maternal role revealed that Chantage [12] studied the maternal role of adolescent mothers and found that the activities that adolescent mothers undertook in taking care of their children included breastfeeding, general cleanliness, responding to the need and care aspects of any child health problems. These adolescent mothers accepted their mother role. The level for acceptance was at a good level $(X=2.12$, S.D. $=.454)$. The highest score was in the category of feeling happy when they touched or carried their children (X = 2.25 , S.D. $=.638$ ).

Srisomboon, Serisathien, Yusamran, and Phahuwatanakorn studied the effect of a maternal role promoting program on maternal role attainment in 


\section{Medical Journal of Clinical Trials \& Case Studies}

adolescent mothers with unplanned pregnancies. This study aimed to examine the effect of a maternal role promoting program on maternal role attainment in adolescent mothers with unplanned pregnancies in Sappasitthiprasong Hospital, Ubonratchatanee Province, Thailand. The results showed that after receiving the maternal role promoting program, adolescent mothers in the experimental group had maternal role attainment scores at 4 weeks postpartum at a rate significantly higher than those in the control group $(\mathrm{p}<.001)$.

Narong [13] studied the effects of the maternal roles enhancing program on perception of family support and success in maternal role attainment among postpartum adolescents. The sample consisted of 60 postpartum adolescents at a tertiary care hospital in the east of Thailand. The results revealed that a mean perception of family support score in the experimental group was significantly higher than those in the control group ( $p$ $<.05$ ). The mean success of maternal roles attainment score in the experimental group was significantly higher than that in the control group $(p<.05)$.

Srisawat, Vichitsukon, and Prasopkittkun studied the effect of promoting grandmothers' role in providing breastfeeding support for first-time mothers. The study subjects included 50 dyads of grandmothers and firsttime mothers after normal delivery at SaiNoi Hospital, Nontaburi Province, Thailand. The results revealed that the grandmothers in the experimental group provided better breastfeeding support than those in the control group as perceived by the mothers.

Noppatanakal and Jirapaet [14] studied the effect of a maternal roles promotion with computer-assisted instruction program on newborn care behavior of primipara adolescent mothers. The sample consisted of 44 pairs of vaginal delivery primiparous adolescent mothers aged 15 to 19 years old. They were admitted to the postpartum wards in community hospitals of the Ministry of Public Health in Nakhonratchasima Province, Thailand. The result revealed that the mean score of newborn care behavior of primiparous adolescent mothers receiving the maternal role promotion with computer-assisted instruction program was significantly higher than that of mothers receiving the routine nursing care at the level of .05.

Pongpaiboon, Kritcharoen, and Phonin [15] studied the effects of natural childbirth care on postpartum perineal pain and maternal-infant attachment for the primiparous postpartum women. The participants were
80 primiparous postpartum women aged 17-35 years. The results revealed that was no difference in motherinfant attachment when comparing between groups at 24 and 48 hours.

The maternal-fetal attachment, the women's adaptation to motherhood roles during pregnancy positively affects their self-confidence and life satisfaction in the postpartum period. In addition, maternal-fetal attachment can increase a mother's healthy behaviors with regard to nutrition, appropriate maternal care, and a desire to know about the fetus $[16,17]$.

\section{Conclusion}

In conclusion, engagement is the same as the term attachment, prenatal attachment, maternal-fetal attachment, prenatal bonding, maternal-fetal bonding, prenatal tie, maternal-fetal tie, and maternal-fetal relationship. It refers to the tie between a mother and her fetus by communication, and interaction. The outcome is care seeking, love, protection, health practices, maternal role, and neonatal outcomes.

The review of literature shows that maternal-fetal attachment is a process between pregnant women had develops relationship with her fetus. In the western countries reported that seeing an ultrasound of the fetus, the experience of fetal movement or quickening, the fetal movement counting, the pictorial intervention is effective for maternal-fetal attachment. In addition, In Asia reported that the abdominal palpation of Leopold's maneuvers had effected for maternal-fetal attachment. In Thailand, the most of the interventions specific on the maternal-infant attainment. Study is lacking on the maternal attachment during the antenatal period.

The existing knowledge from review of literature know that the experience of fetal movement or quickening, the fetal movement counting, and abdominal palpation are health practice behavior of women pregnancy during ante period. It is maternal-fetal attachment. It may identify fetal problems early in the woman pregnancy who has no known pregnancy risk factors. In addition, it is convenient for the woman and validates her perceptions of fetal status. But it is not clarify in confidence in maternal role in behavior. Furthermore, if pregnant adolescent is seeing an ultrasound picture of fetus. It can or not to enhance confidence in maternal role in behavior among pregnant adolescents in Thailand. 


\section{Medical Journal of Clinical Trials \& Case Studies}

\section{References}

1. Phillips P, Francis B, Webb S, Bull V (2015) Oxford advanced learner's dictionary international student's edition. $8^{\text {th }}$ (Edn.), New York, NY: Oxford University Press.

2. Eichhorn N (2012) Maternal fetal attachment: Can acceptance of fetal sentience impact the maternalfetal attachment relationship?. Journal of Prenatal and Perinatal Psychology and Health 27(1): 47-55.

3. Peterson SJ, Bredow TS (2013) Middle range theories application to nursing research. $3^{\text {rd }}$ (Edn.), New York, NY: Wolters Kluwer Health/Lippincott Williams \& Wilkins.

4. Ross E (2012) Maternal-fetal attachment and engagement with antenatal advice. British Journal of Midwifery 20(8): 566-575.

5. Hurtado M (2015) A program to improve maternalfetal attachment among Latina mothers: A grant proposal. Degree Master of Social Work. California State University, USA.

6. Alhusen JL (2008) A literature update on maternalfetal attachment. J Obstet Gynecol Neonatal Nurs. 37(3): 315-328.

7. van Bakel HJ, Maas AJ, Vreeswijk CM, Vingerhoets AJ (2013) Pictorial representation of attachment: measuring the parent-fetal relationship in expectant mothers and fathers. BMC Pregnancy Childbirth 13: 138.

8. Nupech C (2013) Maternal-infant bonding of teenage postpartum mothers with full-time parenting and non-full-time parenting. (Unpublished master's thesis). Prince of Songkla University, Songkhla Province, Thailand.

9. Sombutsook P, Chunuan S, Punthmathrith B (2015) A concept analysis of prenatal attachment. Preceeding of more than 2 decades of graduate nursing study,
Faculty of Nursing, Prince of Songkla University, oral presentation 24.

10. Shin HS, Kim JH (2011) Music Therapy on Anxiety, Stress and maternal-fetal attachment in pregnant women during transvaginal ultrasound. Asian Nursing Research 5(1): 19-27.

11. Nishikawa M, Sakakibara H (2013) Effect of nursing intervention program using abdominal palpation of Leopold's maneuvers on maternal-fetal attachment. Reprod Health 210(12): 2-7.

12. Chantage M (2011) Maternal role of adolescent motherhoods.

13. Narong $T$ (2013) Effects of the maternal roles enhancing program on perception of family support and success in maternal roles attainment among postpartum adolescents (Master's thesis). Burapha University, Thailand.

14. Noppatanakal N, Irapaet V (2014) The effect of a maternal roles promotion with computer-assisted instruction program on newborn care behavior of primipara adolescent mothers. Kuakarun Journal of Nursing 21(1): 144-160.

15. Pongpaiboon P, Kritcharoen S, Phoin K (2015) The effects of natural childbirth care on postpartum perineal pain and maternal-infant attachment for the primiparous postpartum women. Songklanagarind Journal of Nursing 35(1): 37-48.

16. Baghdari N, Sadeghi Sahebzad E, Kheirkhah M, Azmoude E (2016) The effects of pregnancyadaptation training on maternal-fetal attachment and adaptation in pregnant women with a history of baby loss. Nurs Midwifery Stud 5(2): e28949.

17. Buahom K, Kala S, Youngwanichsetha S (2016) The effect of progressive muscular relaxation with husband support on stress of teenage pregnancy women. Prince of Narathivas University Journal 9(2): 38-51. 